\title{
ARGUMENTAÇÃO EM AULAS DE QUÍMICA: ESTRATÉGIAS DE ENSINO EM DESTAQUE
}

\author{
Ariane Baffa Lourenço e Salete Linhares Queiroz ${ }^{\mathrm{a}, *,(\mathbb{C}}$ \\ anstituto de Química de São Carlos, Universidade de São Paulo, 13560-970 São Carlos - SP, Brasil
}

Recebido em 04/04/2020; aceito em 10/06/2020; publicado na web em 21/07/2020

\begin{abstract}
ARGUMENTATION IN CHEMISTRY CLASSES: TEACHING STRATEGIES IN THE SPOTLIGHT. Research in the area of science teaching has highlighted the importance of using argumentation in the classroom, as well as preparing teachers to undertake and conduct activities of this nature. In order to bring elements that contribute to the progress of discussions about the subject, we investigated implementing and developing two teaching strategies (ludic activities and chemistry experiments) in lessons taught by pre-service teachers in supervised internships and we identified their pro-argumentation actions. The results showed that pre-service teachers not fully achieved the task of promoting argumentation practices in chemistry classes, emphasizing their ease and difficulties throughout the activity.
\end{abstract}

Keywords: teaching strategy; argumentation; chemistry; pre-service teachers.

\section{INTRODUÇÃO}

A linguagem tem um papel fundamental na construção e divulgação da ciência. A partir do seu funcionamento os fatos ganham significados, consensos sobre as explicações científicas são alcançados e o ensino e a aprendizagem são concretizados. ${ }^{1}$ Nessa perspectiva, a argumentação possibilita que os indivíduos desenvolvam habilidades cognitivas e discursivas, as quais são essenciais à construção do conhecimento e ao exercício da reflexão. Ao argumentar o indivíduo tem a possibilidade de formular seus pontos de vista e fundamentá-los mediante justificativas que sejam aceitáveis e rever o conteúdo dos mesmos, considerando perspectivas contrárias às suas. ${ }^{2}$

No contexto escolar observa-se que a argumentação tende a ser promovida com base na discussão de temas considerados polêmicos. ${ }^{2}$ O que leva muitos a considerar que a argumentação está, necessariamente, vinculada a eles. Fazendo uma relação com o ensino de ciências naturais, mas especificamente com o ensino de química, observa-se que principalmente temas sociocientíficos são abordados em uma perspectiva argumentativa. Em contraponto, Chiaro e Leitão ${ }^{2}$ sugerem que é necessária a identificação e a análise de tipos de ações discursivas que favoreçam o surgimento de argumentação, inclusive sobre temas curriculares.

Walker e Sampson, ${ }^{3}$ no contexto do ensino de química, corroboram a colocação de Chiaro e Leitão, ${ }^{2}$ uma vez que analisaram se a habilidade de graduandos em argumentar foi desenvolvida em aulas de química geral (nas quais são tratados temas curriculares), a partir da realização de atividades pautadas em modelo instrucional específico, que enfatiza a estrutura de argumentos científicos. Os resultados indicaram que as atividades tiveram impacto positivo na qualidade dos argumentos dos estudantes, presentes inclusive em seus relatórios de laboratório.

Embora a argumentação desempenhe um papel ímpar no contexto escolar, verifica-se que ainda são poucos os professores que estão e são preparados para colocá-la em prática, ou seja, que dispõe de fundamentos teóricos sobre o assunto e vivências que permitam a sua implementação em sala de aula. A referida afirmação é corroborada em publicações da área, como nos trabalhos de Platin ${ }^{1}$ e Ibraim e Justi. ${ }^{4}$ Platin $^{1}$ discute que vários programas oficiais apontam a importância da argumentação em sala de aula, no entanto, não ocorre a

*e-mail: salete@iqsc.usp.b mesma veemência no que tange à incorporação de tais elementos na formação de professores. Para o autor, "Existe uma grande carência na formação teórica e prática dos professores em argumentação: Quem, como e quando serão educados os educadores que querem trabalhar com a argumentação?” (p. 111, tradução nossa).

Já o trabalho de Ibraim e Justi ${ }^{4}$ traz uma investigação sobre como o ensino explícito de argumentação direcionado a licenciandos em química influencia o conhecimento dos mesmos sobre a temática. Os dados revelaram que esse ensino possibilitou o desenvolvimento nos futuros docentes de conhecimentos sobre elementos teóricos da argumentação, estratégias de ensino, materiais instrucionais e ações docentes que potencializam a prática argumentativa.

Em face do exposto e visando contribuir para o progresso de discussões relacionadas à promoção da argumentação em aulas de química, desenvolvemos o presente trabalho, que adiciona elementos e traz uma nova perspectiva frente a questões abordadas em artigo de nossa autoria publicado nesta Revista. ${ }^{5}$ No referido texto, o objetivo foi analisar regências de licenciandas em química, após participarem de uma dinâmica de formação, a qual pretendia oferecer-lhes subsídios na promoção de atividades argumentativas em seu processo de prática docente.

O artigo cumpriu o seu propósito de "amenizar a lacuna existente no que diz respeito a referenciais que abordem as práticas docentes argumentativas de licenciandos, em especial em momento de estágio curricular supervisionado" (p.513), a partir do estabelecimento de relações entre categorias de ações que fomentam processos argumentativos em ambientes de ensino e declarações/afirmações/ solicitações realizadas pelas licenciandas para desencadeamento de ações pró-argumentação.

Este trabalho, em contraponto, tem como objetivo identificar e discutir as facilidades e dificuldades expressas por licenciandos ao desenvolverem aulas de química em uma perspectiva argumentativa, em que fizeram uso de atividades lúdicas (AL) e atividades experimentais (AE), bem como relacionar as referidas facilidades e dificuldades com as ações pró-argumentação identificadas na prática docente dos licenciandos. A partir disso pretende-se apontar questões fulcrais a considerar em iniciativas de formação de professores voltadas à promoção da argumentação em sala de aula. Ou seja, buscamos trazer contribuições para o professor formador do ensino superior na preparação de futuros professores de ciências no que tange ao assunto em pauta. 
As estratégias citadas foram tomadas como alvo de investigação devido à recorrência do seu uso por parte dos licenciandos no processo de formação vivenciado, o que não é supreendente, pois são amplamente disseminadas, como atestam publicações nesta Revista. ${ }^{6,7}$

\section{PERCURSO METODOLÓGICO E REFERENCIAL TEÓRICO DE ANÁLISE}

Tendo em vista o alcance do objetivo citado, investigamos o funcionamento das AL e AE em regências ministradas por licenciandos em química sobre conteúdos curriculares em aulas do ensino médio, no contexto do estágio supervisionado. Seis licenciandos, matriculados em disciplina de Prática de Ensino de Química (PEQ), participaram da pesquisa, desenvolvida em uma universidade pública do Estado de São Paulo. A disciplina em questão, de caráter anual, tem como objetivo a preparação dos mesmos para a docência em química. Na ocasião em que os dados foram coletados a disciplina contava com uma dinâmica de formação que buscava proporcionar aos licenciandos conhecimentos teóricos sobre a argumentação científica em sala de aula. ${ }^{5}$

A referida dinâmica abarcou o seguinte conjunto de atividades: oficina de leitura com discussão de artigos sobre argumentação; aulas expositivas dialogadas proferidas pelo docente da disciplina de PEQ sobre argumentação; jogo envolvendo análise de argumentos; análise de episódios de ensino em uma perspectiva argumentativa; elaboração por parte dos licenciandos de critérios favoráveis ao desencadeamento da argumentação em sala de aula; elaboração de forma individual pelos licenciandos de projetos de regência voltados ao ensino de química em aulas do ensino médio em uma perspectiva argumentativa; análise dos projetos de regência em um processo de peer-review entre os discentes da disciplina; reelaboração dos projetos de regência para a redação da versão final; implementação dos projetos de regência em aulas de química do ensino médio e análise das regências.

Após os licenciandos participarem da dinâmica de formação foi realizado um estudo para obtenção de um panorama do que entendiam sobre argumentação e dos benefícios que confere à prática docente. Os resultados estão reportados em trabalho de nossa autoria intitulado Pre-service chemistry teachers' beliefs about argumentation and argumentative practice ${ }^{8}$ e encontram-se resumidos a seguir: no que tange à argumentação, todos eles a consideraram como um caminho para expressar ideias e opiniões com a intenção de convencer o público, usando para isso argumentos válidos com base científica. Já os benefícios da prática argumentativa foram identificados em dois conjuntos, os relacionados a argumentar para aprender e aprender para argumentar. ${ }^{3}$

Além da participação na dinâmica mencionada, os licenciandos tiveram oportunidade de discutir nas aulas diferentes estratégias de ensino. As estratégias AL e AE foram estudadas em oficina de leitura, a partir do uso de um blog da disciplina, em que cada licenciando, após a leitura de um artigo específico, postava duas questões, as quais eram respondidas por um colega no blog e compartilhadas em contexto de sala de aula, quando discussões eram suscitadas na busca de uma melhor compreensão do assunto em questão. ${ }^{5}$ A oficina de leitura foi inspirada em proposta de Barro et al.,${ }^{9}$ com o blog funcionando como estratégia pedagógica. A AL foi discutida com base no artigo Júri químico: uma atividade lúdica para discutir conceitos de química,$^{10}$ enquanto a AE foi discutida com base no artigo A estratégia "laboratório aberto" para a construção do conceito de temperatura de ebulição e a manifestação de habilidades cognitivas. ${ }^{11}$

Após participarem da dinâmica de formação em argumentação e das discussões sobre as estratégias os licenciandos elaboraram, individualmente, um projeto de regência no qual mencionaram os conteúdos que iriam abordar e as ações que utilizariam para a promoção da argumentação nas suas aulas. Os projetos foram apresentados na disciplina, tendo em vista a sua adequação à realização de regências de química em escolas da Educação Básica que desencadeassem práticas argumentativas.

As regências foram ministradas em aulas de química do ensino médio em escolas públicas e particulares. As informações quanto às temáticas abordadas nas regências e todas as estratégias empregadas, assim como a quantidade de aulas utilizadas e o tipo de escola onde a regência ocorreu, estão no Quadro 1.

Destaca-se que os nomes apresentados neste artigo são fictícios e que a licencianda Ana foi a única que lançou mão das duas estratégias em questão na sua prática docente. As regências foram gravadas em áudio e vídeo e posteriormente transcritas visando à identificação das estratégias de ensino desencadeadas pelos licenciandos, assim como de ações pró-argumentação que realizaram. Com o intuito de caracterizar de forma mais ampla essas estratégias, o projeto de regência e os relatórios de regência também foram analisados. As

Quadro 1. Relação dos temas das regências de cada licenciando juntamente com a quantidade de aulas utilizadas, as estratégias de ensino empregadas, série escolar e o tipo de instituição onde as aulas foram ministradas

\begin{tabular}{|c|c|c|c|c|}
\hline Licencianda & $\begin{array}{c}\text { Tema da regência/série } \\
\text { escolar }\end{array}$ & Estratégia de ensino & Quantidade de aulas* & Tipo de instituição \\
\hline Ana & $\begin{array}{c}\text { Ligações Metálicas } / 1^{\circ} \text { ano } \\
\text { EM }\end{array}$ & $\begin{array}{l}\text { Estratégia lúdica } \\
\text { Atividade experimental } \\
\text { Método cooperativo de } \\
\text { aprendizagem jigsaw }\end{array}$ & 4 & particular \\
\hline Cíntia & $\begin{array}{l}\text { Radioatividade - Fusão e } \\
\text { Fissão Nuclear } / 1^{\circ} \text { ano EM }\end{array}$ & $\begin{array}{c}\text { Estratégia lúdica } \\
\text { Método cooperativo de } \\
\text { aprendizagem jigsaw }\end{array}$ & 4 & pública \\
\hline Mara & $\begin{array}{c}\text { Reações Orgânicas - } \\
\text { Oxidação do Álcool } \\
\text { (Bafômetro) } / 1^{\circ} \text { ano EM }\end{array}$ & Atividade experimental & 4 & pública \\
\hline Naiara & $\begin{array}{l}\text { Lei de Hess e Energia de } \\
\text { Ligação } / 3^{\circ} \text { ano EM }\end{array}$ & Estratégia lúdica & 4 & pública \\
\hline Sergio & $\begin{array}{l}\text { Lei de Hess e Energia de } \\
\text { Ligação/ } 3^{\circ} \text { ano EM }\end{array}$ & Estratégia lúdica & 4 & pública \\
\hline Valter & Oxidação/2 $2^{\circ}$ ano EM & Atividade experimental & 4 & pública \\
\hline
\end{tabular}

* Duração de cada aula: 50 minutos. 
referidas produções foram realizadas com base em orientações prévias entregues aos licenciandos.

No projeto de regência foi solicitada a indicação dos conceitos científicos que seriam abordados, das estratégias que seriam utilizadas, com destaque para as que promoveriam a argumentação. Além disso, os licenciandos indicaram uma proposta de avaliação e apresentaram o plano de aula. Quanto aos dois relatórios solicitados, os mesmos foram elaborados pautados nas orientações a seguir. No primeiro, os licenciandos deveriam responder e refletir acerca de questões que versavam sobre: comparação entre as atividades desenvolvidas em sala de aula e as planejadas no projeto de regência; dificuldades/facilidades encontradas no planejamento de aulas de química em uma perspectiva argumentativa; obstáculos enfrentados na implementação da regência e adaptações necessárias; participação dos alunos frente às atividades propostas e aspectos da argumentação contemplados na regência. Para a elaboração do segundo relatório os alunos tiveram acesso às gravações de suas regências e discorreram sobre os episódios de suas aulas destinados à promoção da argumentação e nas dificuldades/facilidades encontradas nesse processo. A identificação das dificuldades/facilidades apresentadas pelos licenciandos nos relatórios ocorreu com base no referencial de Análise de Conteúdo. ${ }^{12}$ Para tanto, foi adotado o procedimento recorrente e amplamente conhecido na literatura, que envolveu a preparação das informações, a transformação do conteúdo em unidades de análises, a classificação das unidades em categorias que expressavam as facilidades e dificuldades da prática argumentativa, seguido de sua descrição e interpretação.
As ações pró-argumentação dos licenciandos ao desenvolverem as estratégias de ensino nas suas regências foram identificadas com base no Quadro Analítico proposto por Simon et al. ${ }^{13}$ (Quadro 2).

Com base no Quadro Analítico em questão, os autores deste trabalho analisaram as falas dos licenciandos durante a implementação de suas regências. No decorrer do texto são feitas menções às ações pró-argumentação realizadas pelos licenciandos, indicadas por uma letra, e as respectivas categorias a que pertencem, representadas por um numeral. Um exemplo dessa categorização encontra-se no trecho a seguir, o qual foi enquadrado em Encoraja a apresentação das ideias dos alunos ( $3 \boldsymbol{a})$, pois a licencianda Naiara conduz a atividade para que os alunos exponham suas opiniões sobre as colocações dos colegas.

Vocês do fundo, o grupo do Adriano, vocês. Amarela né? Quem tá com a resposta do grupo do Adriano lá, a cartolina amarela? Aí fala pra mim, pode abrir ela? Fala pra mim se a resposta dele, do grupo dele tá certa ou não. A resposta mesmo é a maior? As outras são os passos que ele teria que fazer pra chegar no resultado. Ação $3 \boldsymbol{a}$, Licencianda Naiara.

\section{RESULTADOS E DISCUSSÃO}

Neste tópico são relatadas e discutidas as ações desenvolvidas pelos licenciandos com o intuito de implementação da argumentação em aulas de química e as facilidades e/ou dificuldades enfrentadas para tal prática no contexto de AL e AE, e a relação dessas com as ações pró-argumentação.

Quadro 2. Categorias de ações, adaptadas do trabalho de Simon et al, ${ }^{13}$ que fomentam processos argumentativos em ambientes de ensino e declarações/afirmações/solicitações realizadas pelo professor para desencadeamento dos referidos processos (categorias de ações pró-argumentação)

\begin{tabular}{|c|c|}
\hline Categorias de Simon, Erduran e Osborne ${ }^{13}$ & $\begin{array}{c}\text { Declarações/afirmações/solicitações dos professores para desencadeamento dos processos } \\
\text { argumentativos }\end{array}$ \\
\hline Falar e ouvir (1) & $\begin{array}{l}\text { Incentiva a discussão entre os alunos (1a) } \\
\text { Incentiva os alunos a escutarem as opiniões dos colegas (1) }\end{array}$ \\
\hline Conhecer o significado do argumento (2) & $\begin{array}{l}\text { Define argumento (2a) } \\
\text { Apresenta exemplos de } \operatorname{argumentos}(\mathbf{2} \mathbf{b}) \\
\text { Faz questionamentos sobre a dinâmica envolvida no processo de argumentação (2c) }\end{array}$ \\
\hline Posicionar-se na construção dos argumentos (3) & $\begin{array}{l}\text { Encoraja a apresentação das ideias dos alunos (3a) } \\
\text { Incentiva os alunos a se posicionarem na apresentação das suas ideias (3b) } \\
\text { Valoriza diferentes pontos de vista dos alunos (usualmente na aplicação de estratégias de ensino } \\
\text { mais elaboradas) (3c) }\end{array}$ \\
\hline Justificar com evidências (4) & $\begin{array}{l}\text { Avalia ou confere se as justificativas são subsidiadas por evidências (4a) } \\
\text { Fornece evidências que subsidiem as ideias dos alunos (4b) } \\
\text { Solicita justificativas para as conclusões dos alunos (4c) } \\
\text { Enfatiza a importância de apresentação de justificativas (4d) } \\
\text { Estimula a apresentação de novas justificativas em adição às apresentadas inicialmente (4e) }\end{array}$ \\
\hline Construir argumentos (5) & $\begin{array}{l}\text { Elabora estratégias de ensino-aprendizagem (ex: debates, resolução de problemas sociocientíficos } \\
\text { etc) que permitam a solicitação aos alunos da construção de argumentos na forma escrita e oral (5a) }\end{array}$ \\
\hline Avaliar argumentos (6) & $\begin{array}{l}\text { Incentiva a avaliação dos argumentos pelos alunos (6a) } \\
\text { Incentiva a reflexão sobre o que é necessário para a construção de um bom argumento, considerando } \\
\text { as evidências que o sustentam }(\mathbf{6 b})\end{array}$ \\
\hline Contra-argumentar/Debater (7) & $\begin{array}{l}\text { Incentiva a contra-argumentação frente a argumentos apresentados pelos colegas (7a) } \\
\text { Incentiva a contra-argumentação durante a realização de debates e interpretações de papel (role- } \\
\text { play) (7b) }\end{array}$ \\
\hline Refletir sobre o processo de argumentação (8) & $\begin{array}{l}\text { Estimula a reflexão sobre os processos adotados pelos alunos para a construção do argumento (8a) } \\
\text { Questiona os alunos sobre as mudanças nas suas opiniões, decorrentes dos processos adotados para } \\
\text { a construção do argumento }(\mathbf{8 b})\end{array}$ \\
\hline
\end{tabular}




\section{Atividades lúdicas}

As AL caracterizam-se por criar espaços divertidos onde os alunos podem desenvolver a imaginação, refletir, expressar-se livremente e interagir com os pares sobre conceitos científicos. ${ }^{14,15}$ No contexto do presente trabalho a AL foi colocada em funcionamento pelos licenciandos Cíntia, Ana, Sergio e Naiara. Eles buscaram, cada um à sua maneira, contemplar em suas regências aspectos lúdicos e pedagógicos. Cíntia abordou, por meio do que denominou de "jogo das figuras", o tema radioatividade. Para isso entregou a grupos de alunos figuras com objetos atingidos pela radioatividade, de modo a que compartilhassem suas ideias e indicassem se consideravam os efeitos da radioatividade apresentados nas imagens como benéficos ou maléficos. Tal compartilhamento foi feito inicialmente em pequenos grupos e depois com a sala inteira, seguida de uma discussão conduzida pela licencianda a respeito dos efeitos dela decorrentes. Indícios da efetividade do emprego da AL na promoção da argumentação podem ser observados no trecho a seguir, quando a licencianda visou à criação de um ambiente onde os alunos pudessem expressar-se livremente sobre os conceitos científicos relacionados à temática, com adição da argumentação.

CÍNTIA: O resultado obtido com a dinâmica das figuras foi muito interessante, pois em sua maioria, os alunos associaram as imagens entregues apenas a aspectos negativos causados pela radiação (...). Na última aula, quando da aplicação da dinâmica das figuras, muitos alunos que não se manifestaram nas outras aulas levantaram a mão para poder $\underline{\operatorname{argumentar} \mathrm{e}}$ participar, no que fica evidente uma mudança de conduta, acarretando em participação efetiva dos mesmos (grifo nosso). Fonte: segundo relatório.

A licencianda Cíntia aponta que durante o desenvolvimento da AL enfrentou facilidades e dificuldades para desenvolver a argumentação dos seus alunos. Com relação às facilidades, considera que o fato dos alunos manterem com ela uma relação de empatia contribuiu ao desenvolvimento da argumentação. Ela pondera ainda que os alunos somente começaram a argumentar conforme aprendiam os conceitos e destaca que o fato da AL criar um ambiente de conflito cognitivo facilitou o processo argumentativo. Considerações da licencianda sobre esses aspectos podem ser observados nos trechos a seguir.

CÍNTIA: A empatia com os alunos é o ponto inicial para que se consiga desenvolver uma aula argumentativa. Apesar de não ter feito o estágio de observação com eles, acho que isto não atrapalhou para que os mesmos participassem da aula ... é muito difícil querer a participação do aluno se não for fornecido embasamento teórico para este. Prova disso, é que no primeiro dia ... estes participaram pouco ... no entanto, no último dia, munidos dos conceitos dados nas aulas anteriores, os alunos se sentiram mais confiantes para participar e puderam sustentar a discussão proposta, o que foi bastante significativo (grifo nosso). Fonte: segundo relatório.

CÍNTIA: o conflito causado por conta de imagens com aspectos variados foi importante para fomentar os questionamentos e argumentação por parte destes. Ou seja, causar conflitos conceituais é importante não apenas para que o aluno assimile um conhecimento novo a ele apresentado - conforme descrito pela perspectiva construtivista de Ausubel - mas também é extremamente útil para que o aluno argumente e, desta forma, construa seu conhecimento de maneira mais significativa (grifo nosso). Fonte: primeiro relatório.
Com relação às dificuldades enfrentadas para o desenvolvimento da argumentação, a licencianda considera que o fato dos alunos, em geral, serem submetidos a aulas no formato tradicional, em que não possuem espaços para expressarem-se livremente, dificulta o desenvolver de uma prática argumentativa, conforme primeiro excerto ilustrado na sequência. Além disso, são dificultadores da promoção da argumentação a falta de embasamento teórico sobre o assunto alvo da argumentação e o fato de aulas com viés argumentativo requerem, usualmente, um período maior para execução. Considerações da licencianda nessas perpectivas estão apresentadas nos trechos a seguir.

CÍNTIA: Uma das dificuldades (para implementar a argumentação) pode ser apontada como o fato de que eles estão acostumados com um sistema mais formal de ensino, onde o professor detém a palavra e os alunos não são muito convidados a falar, tampouco a conversar com um colega a respeito do próprio conteúdo dado, ainda mais, por indicação do próprio professor. Ainda em relação ao aspecto supracitado, é nítido que os alunos possuem um pouco de dificuldade na formulação de argumentos, ou por falta de embasamento científico para tanto, ou por não conseguirem expressar oralmente o que pensam de forma consistente. Nesse sentido, ressalta-se então, inicialmente, um pouco de resistência dos alunos à adesão de novas metodologias, perdurando neles muito da conduta de um aluno habituado com o método tradicional de ensino (grifo nosso). Fonte: primeiro relatório.

CÍNTIA: Outro quesito que caracterizou-se como empecilho foi o tempo. O tempo é um problema em se tratando de aulas argumentativas. Este tipo de aula é extensa, justamente por ser mais livre, pois uma discussão demanda argumentos, contra-argumentos, explicações adicionais, questionamentos variados, e teoricamente, nunca se tem noção exata de onde uma conversa termina (grifo nosso). Fonte: primeiro relatório.

Considerando as ações da licencianda Ana para abordar o tema metais, foi feito uso do que ela denominou de "dinâmica de apresentação", dispondo sobre uma mesa diferentes materiais e solicitando aos alunos que escolhessem aqueles pertencentes a essa classe. De acordo com a licencianda, tal dinâmica possibilitou que eles desenvolvessem sua argumentação, resgatando conhecimentos prévios, conforme pode ser observado no trecho a seguir. A ludicidade encontrou espaço em momentos nos quais os alunos escolheram livremente os materiais e envolveram-se em ações pautadas na criatividade e espontaneidade para a elaboração da explicação sobre a razão do material selecionado enquadrar-se como um metal. Além disso, durante a atividade os alunos interagiram livremente com os colegas e com a licencianda.

ANA: Durante a dinâmica, os alunos tiveram que argumen-

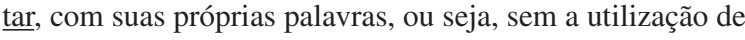
termos técnicos, porque consideravam o objeto escolhido como metal [...]. Com a dinâmica de envolver objetos que eles têm contato no cotidiano, buscou-se despertar o interesse dos alunos e também a curiosidade de pensar em outros objetos que não estavam inseridos na aula que seriam feitos de metais (grifo nosso). Fonte: segundo relatório.

Com relação às facilidades identificadas por Ana para o desenvolvimento da argumentação, apenas um aspecto foi apontado: a temática da aula, a qual estava vinculada a aspectos do cotidiano, no caso os metais. Em contraponto, as dificuldades são referentes à inexperiência da própria licencianda em desenvolver atividades dessa 
natureza, em especial com o intuito de promover a argumentação, e a timidez dos alunos em expressarem suas ideias. Tais considerações podem ser observadas nos trechos a seguir.

ANA: A facilidade que encontrei foi que esta se mostrou uma forma de despertar o interesse dos alunos, de como os metais, assunto a ser abordado na aula, estão presentes no nosso cotidiano (grifo nosso). Fonte: primeiro relatório.

ANA: A dificuldade inicial encontrada foi a timidez dos alunos, o que foi melhorando durante a aula, no decorrer das atividades. Outra dificuldade encontrada foi a difícil construção de argumentos dos alunos sobre o porque do material escolhido ser um metal, mas acredita-se que este fator tem influência do primeiro citado, a timidez de alguns alunos (grifo nosso). Fonte: primeiro relatório.

Para desenvolver a AL, Sergio e Naiara possuíam o mesmo tema de regência, lei de Hess e energia de ligação, e conduziram o que chamaram de "jogo didático". O jogo constituiu, inicialmente, na separação dos alunos em grupos; em seguida, cada grupo recebeu um conjunto de equações parciais com seus respectivos valores de variação de entalpia, assim como a representação da equação global que havia sido destinada a outro grupo. Após cada grupo apresentar as equações globais referentes às suas equações parciais, os grupos que possuíam as respostas esperadas para tais equações analisavam as respostas dos colegas e promoviam uma discussão sobre a sua pertinência, ou não.

Com relação às facilidades e dificuldades identificadas pelos licenciandos para o desenvolvimento da AL em uma perspectiva argumentativa, Sergio aponta apenas um aspecto como facilidade: a interação com os alunos. Nessa perspectiva, pondera que uma vez sanada a dificuldade de empatia com os alunos, a aula fluiu de maneira a facilitar a argumentação. Dentre as dificuldades mencionadas está a falta de familaridade do licenciando com a turma e a temática da aula, uma vez que considera que o tema tratado não proporcionou um ambiente facilitador da argumentação. Considerações do licenciando nessas perpectivas estão apresentadas nos trechos a seguir.

SERGIO: Acredito que a facilidade a ser apontada seria com relação à interação com os alunos, pois passados os primeiros momentos de ansiedade e adaptação dos alunos a receptividade ao novo professor pode ser avaliada como muito boa, refletida por várias vezes na boa participação e no empenho que tiveram na realização das atividades (grifo nosso). Fonte: primeiro relatório.

SERGIO: Um fator que dificultou a promoção da argumentação ... é o fato de a turma não estar habituada com o professor (estagiário), nesse caso a atividade demanda mais tempo para ser realizada do que o normalmente necessário até que a turma se sinta à vontade com o novo professor ... outro fator que dificultou a promoção da argumentação foi o tema proposto (grifo nosso). Fonte: primeiro relatório.

A licencianda Naiara aponta apenas um aspecto como facilidade: o fato da atividade ter sido realizada em grupo favoreceu a argumentação, via discussão e exposição de ideias. De mesma forma, somente uma dificuldade foi identicada pela licencianda: o fato dos alunos estarem acostumados a um ensino tradicional, com poucas oportunidades de expressarem-se. Considerações sobre os apontamentos de Naiara estão apresentadas a seguir.
NAIARA: As atividades propostas de resolução das equações foram desenvolvidas em grupos o que favoreceu a discussão e exposição de ideias (grifo nosso). Fonte: primeiro relatório.

NAIARA: A maior dificuldade em se promover a regência argumentativa é a forma como os alunos participam da aula, é bastante difícil conseguir que eles somente respondam o que lhes é perguntado, quanto mais, expor suas idéias e esperar que outro aluno lance um contra-argumento. Infelizmente, os alunos observados não têm esse hábito, não estão acostumados com aulas que lhes exija uma maior reflexão, busca de idéias (grifo nosso). Fonte: primeiro relatório.

A seguir, as ações pró-argumentação dos licenciandos durante a aplicação de AL, com base na perspectiva do referencial adotado ${ }^{13}$ são discutidas e relacionadas com as facilidades e dificuldades expressas pelos licenciandos no desenvolvimento de aulas em uma perspectiva argumentativa, com base na estratégia de AL.

Compilando as facilidades identificadas pelos licenciandos ao implementarem aulas em uma perspectiva argumentativa tem-se: empatia dos alunos com o licenciando, ambiente potencializador de conflito conceitual, temática da aula (temas vinculados ao cotidiano), formato de atividades em grupo e conhecimento do aluno sobre o assunto. Quanto às dificuldades tem-se: alunos acostumados a aulas tradicionais, falta de conhecimento prévio dos alunos sobre o assunto, aula argumentativa pode exigir um tempo maior para execução, inexperiência do licenciando em desenvolver atividades argumentativas, timidez dos alunos em exporem suas ideias, falta de familiaridade do licenciando com os alunos e temática da aula (temas não vinculado ao cotidiano).

As ações pró-argumentação identificadas, relacionadas a cada um dos licenciandos constam no Quadro 3.

A ação elabora estratégias de ensino-aprendizagem que permitam a solicitação aos alunos da construção de argumentos na forma escrita e oral (5a), pertencente à categoria construir argumentos, foi realizada por todos os licenciandos, cada um à sua maneira, via implementação de AL. A pertinência da escolha dos licenciandos na adoção da AL para promoção da argumentação está perfeitamente em concordância com estudos reportados na literatura. De fato, embora sem contemplar a discussão sobre facilidades e dificuldades enfrentadas para tanto, Fujii ${ }^{16}$ e Zanon et al.${ }^{17}$ apontam que a referida estratégia fomenta a argumentação. Fujii ${ }^{16}$ constatou o favorecimento de ambiente argumentativo em aulas nas quais alunos do ensino médio e superior participaram de um roleplaying game sobre conceitos de biologia. Já Zanon et al. ${ }^{17}$ com base na implementação e avaliação do jogo ludo químico, sugerem que os aspectos lúdicos e cognitivos do jogo desenvolvem, dentre outros aspectos, a argumentação.

A ação encoraja a apresentação das ideias dos alunos (3a), pertencente à categoria posicionar-se na contrução do argumento, $\mathrm{e}$ a ação fornece evidências que subsidiem as ideias dos alunos (4b), pertencente à categoria justificar com evidências, também foram contempladas por Ana, Cíntia, Naiara e Sergio.

Quanto à identificação de ação em que os licenciandos criam espaços para os alunos apresentarem suas ideias (3a), essa não é surpreendente no contexto de AL. De fato, em atividades desse naipe a apresentação de ideias é um dos meios centrais para os alunos interagirem com os demais, o que acaba por propiciar o referido encorajamento aos alunos, por parte do professor, além do conhecimento das suas concepções e intenções frente ao tema em estudo. ${ }^{18}$

A identificação de ação em que são fornecidas evidências aos alunos, em sua maioria pautadas na discussão de conceitos científicos (4b), coloca os alunos em contato com conhecimentos sobre o tema estudado e se aproxima do discurso padrão de sala de aula denominado 
Quadro 3. Ações pró-argumentação nas regências pautadas em AL

\begin{tabular}{|c|c|c|c|c|c|c|c|c|}
\hline & \multicolumn{8}{|c|}{$\begin{array}{c}\text { Declarações/afirmações/solicitações realizadas pelos licenciandos para o desencadeamento dos processos argumentativos durante as } \\
\text { regências }\end{array}$} \\
\hline & $1 \mathrm{a}$ & $1 \mathrm{~b}$ & $3 a$ & $3 b$ & $4 \mathrm{~b}$ & $4 \mathrm{c}$ & $4 \mathrm{e}$ & $5 \mathrm{a}$ \\
\hline \multicolumn{9}{|c|}{ Licenciandos } \\
\hline Ana & & & $\bullet$ & & $\bullet$ & - & - & $\bullet$ \\
\hline Cíntia & $\bullet$ & $\bullet$ & $\bullet$ & $\bullet$ & $\bullet$ & $\bullet$ & & $\bullet$ \\
\hline Naiara & & $\bullet$ & $\bullet$ & & $\bullet$ & $\bullet$ & & $\bullet$ \\
\hline Sergio & & - & • & & - & & & • \\
\hline
\end{tabular}

$1 \mathrm{a}=$ incentiva a discussão entre os alunos; $1 \mathrm{~b}=$ incentiva os alunos a escutarem as opiniões dos colegas; $3 \mathrm{a}=$ encoraja a apresentação das ideias dos alunos; $3 \mathrm{~b}=$ incentiva os alunos a se posicionarem na apresentação das suas ideias; $4 \mathrm{~b}=$ fornece evidências que subsidiem as ideias dos alunos; $4 \mathrm{c}=$ solicita justificativas para as conclusões dos alunos; $4 \mathrm{e}=$ estimula a apresentação de novas justificativas em adição às apresentadas inicialmente e 5a = elabora estratégias de ensino-aprendizagem que permitam a solicitação aos alunos da construção de argumentos na forma escrita e oral.

IRF (Iniciação do professor, Resposta do aluno, Feedback do professor). Nesse padrão o professor fornece as evidências, configuradas nos conceitos científicos, faz uma pergunta ao aluno e fornece um retorno. ${ }^{19}$ Assim, o resultado está alinhado com os depoimentos anteriores, pois a aplicação dessa ação pró-argumentação não é dificultada em turmas de alunos acostumados a aulas tradicionais, que foi justamente a situação identificada pelos licenciandos durante as regências. Ou seja, embora os licenciandos tenham apontado como uma das suas dificuldades na promoção da argumentação o fato de os alunos estarem acostumados com esse tipo de aula, tal contexto permitiu que todos eles aplicassem a referida ação pró-argumentação sem maiores obstáculos.

A ação incentiva os alunos a escutarem as opiniões dos colegas (1b), pertencente à categoria falar e ouvir, e a ação solicita justificativas para as conclusões dos alunos (4c), pertencente à categoria justificar com evidências, foram realizadas por três dos quatros licenciandos. Quanto a ambas as ações, o fato de AL ocasionarem, muito frequentemente, interação efetiva entre os alunos, facilita o incentivo, por parte do professor, à escuta das opiniões dos pares e à solicitação de justificativas para as conclusões alcançadas. Dessa forma, o desencadeamento das ações (1b) e (4c) pode ser associado às seguintes facilidades mencionadas pelos licenciandos ao implementarem aulas em uma perspectiva argumentativa: colocação em funcionamento de trabalho em grupo por parte dos alunos e apresentação de situações em aula que potencializem o conflito cognitivo.

Em contraponto, as três ações seguintes foram identificadas apenas para um licenciando, sugerindo a dificuldade que enfrentaram para promover o seu desencadeamento: incentiva a discussão entre os alunos (1a), incentiva os alunos a se posicionarem na apresentação das suas ideias (3b) e estimula a apresentação de novas justificativas em adição às apresentadas inicialmente (4e), são relacionadas, respectivamente, às categorias falar e ouvir, posicionar-se na construção dos argumentos e justificar com evidências.

A baixa frequência em relação à primeira ação (1a) não era esperada, uma vez que ao considerarmos o planejamento da regência dos licenciandos que adotaram a AL como estratégia observa-se a pretensão da criação de espaços em que os alunos expressariam suas opiniões sobre os assuntos em pauta. Além disso, ela poderia ter sido favorecida devido ao caráter da própria AL, que poderia gerar um ambiente em que os alunos interagissem com os pares na discussão sobre conceitos científicos. ${ }^{5,14}$

Com relação à ação incentiva os alunos a se posicionarem na apresentação das suas ideias (3b), essa envolve um ambiente no qual o professor não faz perguntas diretas aos alunos, mas sim cria situações para que apresentem espontaneamente suas ideias. Sua baixa frequência pode ter sido decorrente das dificuldades expressas pelos licenciandos, relacionadas à pouca experiência em conduzir atividades de natureza argumentativa, pelo fato dos alunos não possuírem conhecimento suficientes sobre o assunto para elaborarem um argumento e porque os alunos, em sua maioria, não estão acostumados a apresentar suas ideias de forma argumentativa, visto que são submetidos, em geral, a aulas do tipo tradicional, em que há pouco espaço para o desenvolvimento de habilidades dessa natureza.

Quanto à baixa frequência da ação (4e) essa não é surpreendente, uma vez que para sua ocorrência é fundamental que os alunos apresentem uma justificativa para que o licenciando possa estimular a apresentação de novas justificativas em adição às apresentadas inicialmente. Ou seja, é compreensível que quando o licenciando precisa de uma ação do aluno para realizar outra, nem sempre consegue êxito com facilidade. Além disso, a baixa ocorrência pode estar relacionada também com as dificuldades apresentadas pelos licenciandos da falta de desenvoltura dos alunos da Educação Básica em apresentarem suas ideias de natureza científica, da falta de vivência dos licenciandos em conduzirem atividades em uma perspectiva argumentativa, o que dificultaria o desenvolvimento do ambiente questionador e pelo fato dos alunos estarem geralmente submetidos a um ensino tradicional, em que pouco vivenciam ações de natureza argumentativa.

Além dos aspectos supracitados, a variação da frequência das ações pró-argumentação pode estar relacionada com o próprio perfil dos licenciandos. Tal fato pode ser observado quando se considera o desempenho da licencianda Cíntia. Em detrimento dos demais, observa-se que a mesma apresenta um maior número de ações pró-argumentação, sendo que sua atividade aproxima-se das desenvolvidas pelos seus colegas. Alguns licenciandos podem ter limitado as possibilidades de inserções dos alunos durante a aula com receio de perder o controle da atividade, tendo a falta de experiência em conduzir ações em uma perspectiva argumentativa, também influenciado seu desempenho. Esse último aspecto pode ser observado no trecho a seguir da licencianda Ana. Destaca-se que embora tenha apresentado dificuldade na condução das ações pró-argumentação, a experiência vivenciada, em sua opinião, a preparou para ações futuras similares.

ANA: Foi identificada uma insegurança na aplicação de atividades com foco na argumentação com receio de que o conteúdo a ser abordado não pudesse ser inteiramente tratado por questão de tempo disponível para trabalhar com a turma. Tal insegurança também se deu por conta de não ter tido contato antes com tais estratégias, não sabendo ao certo como aplicá-las e suas implicações, como recepção dos alunos, e se seriam eficazes em promover a argumentação. Outra dúvida em relação a aplicação de tais atividades foi em 
como avaliar os alunos, que material se teria para analisar o que os alunos conseguiram aprender. Todas essas dificuldades foram sanadas após aplicação. Assim, não existe mais tal insegurança supracitada por se saber agora como abordar conteúdo programático através de uma atividade que promova a argumentação (grifo nosso). Fonte: segundo relatório.

A análise dos dados indica também que as ações que trazem em seu bojo características que se aproximam do discurso tradicional em sala de aula, foram contempladas por todos os licenciandos. Nesse contexto temos a ação Encoraja a apresentação das ideias dos alunos (3a) e Fornece evidências que subsidiem as ideias dos alunos (4b).

\section{Atividades experimentais}

As atividades de natureza experimental possibilitam ao aluno questionar fenômenos e propor e investigar hipóteses..$^{20,21}$ Dentre as modalidades da experimentação, destacam-se as AE de demonstração e a de prática de laboratório. A atividade de prática de laboratório é entendida aqui como sendo realizada pelos próprios alunos, com a orientação do professor. A demonstrativa, geralmente, é realizada pelo professor e tem seu foco na ilustração dos fenômenos científicos, podendo ser desenvolvida em uma conotação fechada ou aberta. Na demonstração fechada o foco está no professor e na ilustração do fenômeno, já na aberta busca-se também a criação de um espaço para discussão e exploração do fenômeno estudado por parte dos alunos..$^{22,25}$

No contexto do presente trabalho a AE foi utilizada durante as regências por três licenciandos, a saber: Ana, Valter e Mara. Ana realizou dois experimentos no laboratório de química da escola, um do tipo demonstrativo e outro de prática de laboratório. O primeiro experimento consistiu em uma atividade demonstrativa sobre condutibilidade térmica. Para tanto, foi colocada uma colher de metal e uma de madeira em um recipiente com água quente e foi solicitado aos alunos para que tocassem as duas e relatassem o que identificavam e apresentassem suas ideias sobre a razão da colher de metal estar mais quente. Embora tenha sido um experimento de demonstração, Ana buscou envolver os alunos na atividade de maneira a torná-la com uma conotação aberta.

No segundo experimento a licencianda conduziu com os alunos a produção de uma liga metálica com base em um roteiro pré-estabelecido e solicitou ao final do experimento respostas sobre os fenômenos observados. Embora tenha trabalhado com um roteiro, a licencianda buscou fazer com que os alunos relacionassem o experimento realizado com conhecimentos prévios sobre o assunto, bem como os auxiliou em suas ações, como pode ser observado no trecho a seguir.

ANA: Na atividade de prática experimental, mediei as ações dos alunos de acordo com o roteiro fornecido, além de auxiliar os alunos na parte instrumental, visto que alguns deles ainda não estavam familiarizados com o ambiente laboratorial ... Para a resolução das questões propostas no roteiro de prática, eles também tiveram de buscar informações passadas durante a aula e em material disponibilizado (tabela de ligas metálicas) (grifo nosso). Fonte: segundo relatório.

A licencianda Ana considera que no desenvolver das AE enfrentou algumas dificuldades e facilidades quanto à promoção da argumentação. Com relação à facilidade, ela aponta apenas uma: o envolvimento dos alunos na realização da AE. Ana considera que os alunos se sentiram à vontade para efetuar perguntas e comentários vinculados à prática e aos conteúdos neles abordados, conforme pode ser observado na transcrição a seguir.
ANA: Todos em geral participaram com perguntas e comentários de vivências relacionadas, além de terem mostrado bastante interesse nas atividades experimentais propostas... no experimento, os alunos também tinham de discutir para realizar a prática e responder as questões propostas no roteiro (grifo nosso). Fonte: segundo relatório.

Já as dificuldades enfrentadas por Ana envolvem o fato de os alunos terem dedicado mais tempo à realização da prática de laboratório do que o previsto, assim como a sua insegurança, advinda da inexperiência em desenvolver atividades de natureza argumentativa. Ana pondera que a situação vivenciada forneceu subsídios importantes para ações docente futuras em uma perspectiva argumentativa. Considerações que contemplam tais aspectos estão apresentados a seguir.

ANA: Os alunos demandaram mais tempo do que o estipulado para desenvolver a atividade, o que impossibilitou um fechamento das atividades proposta ... foi identificada uma insegurança na aplicação de atividades com foco na argumentação com receio de que o conteúdo a ser abordado não pudesse ser inteiramente tratado por questão de tempo disponível para trabalhar com a turma. Tal insegurança também se deu por conta de não ter tido contato antes com tais estratégias, não sabendo ao certo como aplicá-las e $\underline{\text { suas implicações, }}$ como recepção dos alunos, e se seriam eficazes em promover a argumentação (grifo nosso). Fonte: segundo relatório.

O licenciando Valter fez dois experimentos do tipo demonstrativo. Com relação ao primeiro experimento, no início da primeira aula Valter realizou uma demonstração da oxidação de uma maçã, cortando-a ao meio, envolvendo uma parte em um plástico e outra não, e questionando os alunos sobre o que aconteceria com as diferentes partes. Ao final da aula foi apresentado o que havia acontecido com cada parte da maçã e conduzida uma discussão sobre os possíveis motivos dos fenômenos observados. Para o segundo experimento o licenciando separou os alunos em pequenos grupos e pediu para que discutissem o que aconteceria com o cobre ao ser mergulhado em uma solução de sulfato de zinco, e com o zinco ao ser mergulhado em uma solução de sulfato de cobre. As hipóteses dos alunos foram escritas em uma folha de respostas e, em seguida, com a apresentação das reações em lousa, estes discutiram e argumentaram sobre os fenômenos envolvidos.

Para os dois experimentos o licenciando buscou criar um ambiente em que os alunos pudessem apresentar suas hipóteses sobre os fenômenos envolvidos no experimento, conforme pode ser observado no trecho a seguir.

VALTER: Enquanto os alunos formalizavam em uma folha de respostas, foi realizada o levantamento de hipóteses, em seguida com as reações montadas em lousa, os alunos discutiram e argumentaram qual elemento oxidaria e qual reduziria, qual ganharia elétrons e qual perderia. (Nessa parte da aula, foi trabalhado, o levantamento de hipóteses, e criação de espaço para os alunos discutirem o assunto abordado) ... Em um segundo momento, perguntas foram direcionadas aos alunos, com o intuito de promover a argumentação, com o tema oxidação, onde os alunos participaram respondendo o que achavam correto e defendendo suas ideias, onde eu conduzia a conversa para uma resposta correta, respeitando a opinião dos alunos e debatendo sobre o assunto (grifo nosso). Fonte: primeiro relatório. 
Quanto às facilidades em implementar a prática experimental, o licenciando Valter aponta os elementos inerentes a uma AE, como o levantamento de hipóteses e a interação entre os sujeitos envolvidos no processo, conforme pode ser observado no trecho a seguir.

VALTER: A experiência prática demonstrativa ajudou muito a conseguir que os alunos falassem, pois eles tinham hipóteses para o que aconteceria ao misturar os reagentes, sendo errado ou certo, houve discussão entre os alunos e entre professor e alunos, essa motivação ajudou a conduzir a aula de uma forma mais dinâmica e com a atenção de todos os alunos (grifo nosso). Fonte: segundo relatório.

O licenciando aponta como dificuldade no desenvolvimento da AE a timidez dos alunos em expressarem-se sobre os conceitos científicos envolvidos e sua inexperiência em práticas docentes de natureza argumentativa. Considerações do licenciando que exemplificam tais aspectos são apresentados a seguir.

VALTER: O principal problema foi a timidez dos alunos, o que me deixou um pouco nervoso e fez com que eu atropelasse algumas etapas para criar os momentos destinados aos alunos a expor suas ideias (grifo nosso). Fonte: primeiro relatório.

A licencianda Mara realizou um experimento em grupo sobre o bafômetro com os alunos, na própria sala de aula, a partir da utilização de um Kit da Experimentoteca do Centro de Divulgação Científica e Cultural da Universidade de São Paulo (CDCC/USP). ${ }^{26}$ Mara buscou atuar em uma perspectiva investigativa, embora o Kit em questão esteja acompanhado de um roteiro pré-estabelecido, como pode ser observado pelo trecho a seguir.

MARA:Tinha-se o objetivo de fazer com que os alunos relembrassem sobre a função orgânica álcool e aprendessem como ocorrem as reações de oxidação desses compostos orgânicos através da experimentação, construindo um bafômetro caseiro, além também de levá-los ao aprendizado da manipulação em experimentos químicos e da obtenção de informações através da observação dos resultados apresentados em um experimento e, do propósito de se trabalhar a argumentação dos alunos através da exposiç̧ão oral e escrita desses sobre o que observaram no experimento, defendendo cientificamente o que de fato estaria acontecendo (grifo nosso). Fonte: segundo relatório.

A licencianda apresentou um único aspecto como facilidade para desenvolver a prática argumentativa a partir da AE: a empatia dos alunos com a mesma. Mara considera que, por ter acompanhado os alunos durante seu período de estágio, obteve durante a implementação da AE, um retorno mais efetivo no entusiasmo da realização da prática.

MARA: Acredito que essa boa relação professor-aluno que fora mantida ao longo da regência teve grande contribuição para que os alunos em nenhum momento se queixassem das estratégias utilizadas em aula ou mostrassem qualquer rejeição (grifo nosso). Fonte: primeiro relatório.

A licencianda aponta três dificuldades para a implementação da AE. Considera que, devido a um problema na organização da escola, precisou fazer sua regência para uma turma do primeiro ano do ensino médio, sendo que o conteúdo da prática, em sua concepção, estava voltado para o público do terceiro ano. Diante desse fato, afirma que faltou aos alunos conhecimento teórico suficiente para formulação de argumentos. Mara aponta também que o fato de os alunos estarem, em geral, habituados a modelos tradicionais de ensino resultou na dificuldade na apresentação de suas hipóteses. Além disso, Mara considera que sua inexperiência na prática docente dificultou a colocação em funcionamento de ações que facilitassem a prática argumentativa. Considerações nessa perspectiva podem ser observadas a seguir.

MARA: Os alunos até expunham alguma opinião, tentavam participar, porém não conseguiam defender suas ideias, argumentar a favor das mesmas. Suas falas eram curtas, sem muita reflexão. Esse resultado foi obtido pelo fato de os alunos não estarem acostumados com atividades nas quais podem expor o que conhecem e o que acreditam, resultado de um ensino tradicional pautado em aulas expositivas, além também do conhecimento prévio limitado, já que o conteúdo era direcionado a outro nível (grifo nosso). Fonte: primeiro relatório.

MARA: Em alguns momentos, por falta de experiência, acabei perdendo oportunidades de fazer com que os alunos buscassem argumentar para explicar fatores observados durante o desenvolvimento da regência, como foi o caso do grupo no qual o experimento não deu certo. Os erros poderiam ser mais bem aproveitados se fosse chamada a atenção da turma toda para o acontecimento e em seguida fosse pedido para que esses buscassem explicações científicas para justificar o ocorrido (grifo nosso). Fonte: primeiro relatório.

Os resultados apresentados a seguir estão relacionados com a análise das ações pró-argumentação ${ }^{13}$ dos licenciandos durante a aplicação de $\mathrm{AE}$, as quais são discutidas e relacionadas com as facilidades e dificuldades apresentadas pelos licenciandos no desenvolver de ações dessa natureza. As facilidades referem-se ao envolvimento dos alunos na realização das $\mathrm{AE}$, a natureza das $\mathrm{AE}$, por possibilitar o levantamento de hipóteses e a interação entre os sujeitos, e à empatia dos alunos com o licenciando. Quanto às dificuldades, tem-se a inexperiência dos licenciandos em desenvolver aulas em uma perspectiva argumentativa, timidez dos alunos, preparação de regência para ser implementada em um segmento do ensino médio e aplicação em outro, falta de conhecimento prévios dos alunos sobre temática da AE e alunos acostumados a aulas tradicionais.

Assim como observado para as AL, ressaltamos que embora nem todos os licenciandos tenham apresentado explicitamente as mesmas facilidades e dificuldades, essas podem ter permeado as suas práticas, contribuindo com a variação de frequência das ações pró-argumentação (Quadro 4)

A ação elabora estratégias de ensino-aprendizagem que permitam a solicitação aos alunos da construção de argumentos na forma escrita e oral (5a), pertencente à categoria construir argumentos, foi realizada por todos os licenciandos via implementação de AE. A pertinência da escolha dos licenciandos na adoção da $\mathrm{AE}$ para promoção da argumentação está alinhada com estudos reportados na literatura. De fato, Colombo et al. ${ }^{27}$ com base no Modelo de Toulmin, ${ }^{28}$ analisaram os diálogos de estudantes do ensino fundamental ao desenvolverem uma $\mathrm{AE}$ em uma perspectiva investigativa e identificaram argumentos produzidos pelos alunos, os quais colaboraram no entendimento de situações físicas e formulação de conclusões. Considerações nessa perspectiva também são apontadas nos trabalhos de Capecchi e Carvalho ${ }^{29}$ ao analisarem, a partir de diferentes referenciais teóricos no campo da argumentação, a fala dos alunos e do professor no desenvolver de atividades de conhecimento físico. 
Quadro 4. Ações pró-argumentação nas regências pautadas em AE

\begin{tabular}{|l|c|c|c|c|c|c|c|}
\hline & \multicolumn{6}{|c|}{ Declarações/afirmações/solicitações realizadas pelos licenciandos para o desencadeamento dos processos argumentativos durante as } \\
& $1 \mathrm{a}$ & $1 \mathrm{~b}$ & $3 \mathrm{a}$ & $3 \mathrm{~b}$ & $4 \mathrm{~b}$ & $4 \mathrm{c}$ & $5 \mathrm{a}$ \\
\hline & & & & & & & \\
\hline Licenciandos & $\bullet$ & & $\bullet$ & & $\bullet$ & $\bullet$ & $\bullet$ \\
\hline Ana & $\bullet$ & $\bullet$ & $\bullet$ & $\bullet$ & $\bullet$ & $\bullet$ & $\bullet$ \\
\hline Mara & & & $\bullet$ & & $\bullet$ & & $\bullet$ \\
\hline
\end{tabular}

$1 \mathrm{a}=$ incentiva a discussão entre os alunos; $1 \mathrm{~b}=$ incentiva os alunos a escutarem as opiniões dos colegas; $3 \mathrm{a}=$ encoraja a apresentação das ideias dos alunos; $3 \mathrm{~b}=$ incentiva os alunos a se posicionarem na apresentação das suas ideias; $4 \mathrm{~b}=$ fornece evidências que subsidiem as ideias dos alunos; $4 \mathrm{c}=$ solicita justificativas para as conclusões dos alunos; $4 \mathrm{e}=$ estimula a apresentação de novas justificativas em adição às apresentadas inicialmente e 5a = elabora estratégias de ensino-aprendizagem que permitam a solicitação aos alunos da construção de argumentos na forma escrita e oral.

A ação encoraja a apresentação das ideias dos alunos (3a), pertencente à categoria posicionar-se na construção do argumento, e a açãofornece evidências que subsidiem as ideias dos alunos (4b), pertencente à categoria justificar com evidências também foram contempladas por Ana, Mara e Valter. Era esperado que a implementação de AE levasse à presença unânime da ação em que os licenciandos criam espaços para os alunos apresentarem suas ideias (3a). Isso porque a $\mathrm{AE}$, especialmente quando tem enfoque investigativo, preza por dar oportunidade aos alunos de apresentar suas hipóteses, investigá-las e refletir sobre suas ideias, ${ }^{20,21}$ e todos os licenciandos se valeram dessa modalidade, seja no formato demonstrativo ou como atividade de laboratório. Tal resultado vem a corroborar com a facilidade apontada por licenciandos de que a natureza da $\mathrm{AE}$ possibilita a criação de um ambiente em que os alunos apresentam suas ideias sobre a temática em estudo, bem como com a facilidade de envolvimento dos alunos, que ao se engajarem na prática experimental irão apresentar suas hipóteses para os fenômenos, como esperado pelos licenciandos.

A identificação de ação em que são fornecidas evidências aos alunos (4b) esteve em sua maioria pautada na discussão de conceitos científicos. Tal fato encontra respaldo em pesquisas reportadas na literatura que afirmam que $\mathrm{AE}$ podem e devem contemplar a discussão de aspectos teóricos do fenômeno abordado. ${ }^{30}$

A ação incentiva a discussão entre os alunos (1a), pertencente à categoria falar e ouvir, e a ação solicita justificativas para as conclusões dos alunos (4c), pertencente à categoria justificar com evidências, foram realizadas por dois dos três licenciandos, Ana e Mara. Quanto às referidas ações, considera-se que foram facilitadas visto que dentre o rol de possibilidades de desenvolvimento das $\mathrm{AE}$ investigativas encontra-se justamente o fato das mesmas criarem situações que possibilitem diálogos, os quais colaboram para consolidação do entendimento dos conceitos, bem como de mudanças conceituais, características que colaboram na criação de espaços para que os alunos manifestassem suas opiniões e hipóteses, estimulando o processo de argumentação e aprendizagem.

Trazemos inferências de que a ação de incentivar a discussão entre os alunos (1a) foi contemplada nas ações da licenciandas Ana e Mara, visto que procederam a questionamentos aos alunos a respeito da prática realizada, o que colaborou para que ocorressem interações entre eles. Além disso, as facilidades de envolvimento entre os alunos e empatia dos alunos com as licenciandas, citadas, respectivamente, por Ana e Mara pode ter contribuído para o desenvolvimento dessa ação.

Com relação à variação da frequência da ação solicita justificativas para as conclusões dos alunos (4c), trazemos uma análise das ações do licenciando Valter, que embora tenha buscado promover a apresentação das ideias dos alunos referente à ação (3a), não contemplou em sua atividade espaços para que os mesmos interagissem entre si, ação (1a), e também não os encaminhou para justificarem suas conclusões, que configuraria a ação (4c). Observa-se que essa última ação está relacionada diretamente à necessidade de haver uma atividade prévia dos alunos e quando o licenciando não tem o retorno desejado, muitas vezes, não consegue proceder as solicitações, conforme destacado pelo licenciando Valter, o que pode ser decorrente da falta de experiência do mesmo em promover atividades em perspectiva argumentativa, bem como da timidez dos alunos.

As ações incentiva os alunos a escutarem as opiniões dos colegas (1b) e incentiva os alunos a se posicionarem na apresentação das suas ideias (3b) são relacionadas, respectivamente, às categorias falar $e$ ouvir e posicionar-se na construção dos argumentos. A característica das AE de possibilitarem momentos de apresentação e discussão de ideias pode favorecer a criação de espaços para os alunos prestarem atenção nas colocações dos colegas (1b) e posicionarem-se e apresentarem suas concepções ( $3 b$ ). Embora a estratégia em questão traga em seu bojo essas possibilidades, somente a licencianda Mara contemplou tais ações ( $1 \mathrm{~b}$ e $3 \mathrm{~b}$ ) em sua regência. Tal resultado pode ser decorrente da dificuldade relacionada à inexperiência dos licenciandos no desenvolvimento de AE em uma perspectiva argumentativa. De fato, esse indício pode ser observado quando o licenciando Valter aponta que devido ao pouco envolvimento dos alunos nas $\mathrm{AE}$ acabou por não realizar ações que permitissem um ambiente favorável à apresentação de ideias deles.

\section{CONCLUSÕES E IMPLICAÇÕES}

Documentos curriculares que pautam o ensino de ciências na Educação Básica destacam a relevância do domínio de conhecimentos científicos na formação de todos, uma vez que tal domínio fornece subsídios para avaliação de problemáticas atuais, realização de escolhas e intervenções frente a questões científicas e tecnológicas. ${ }^{31,32}$ Além da compreeensão conceitual, os documentos apontam como desejável que os estudantes se engajem em processos de pensamento mais complexos e participem de episódios que os confrontem com a necessidade de analisar situações, propor soluções e argumentar a favor das respectivas tomadas de decisão. É nesse contexto que a Base Nacional Comum Curricular (BNCC) ${ }^{32}$ reforça a importância da promoção da argumentação em ambientes de ensino. Em contraponto, essa ação tem se mostrado desafiadora para os professores, ${ }^{33} \mathrm{e}$ não menos instigante tem sido a tarefa dos formadores de professores no sentido de colocar os licenciandos em contato com conteúdos e estratégias que os conduzam a ações didáticas que favoreçam a argumentação. ${ }^{5}$

Retomando a nossa intenção de contribuir com os referidos formadores, a partir dos resultados e da discussão apresentados neste manuscrito, destacamos as seguintes conclusões:

- a inexperiência na lida com atividades didáticas argumentativas, expressa por parte considerável dos licenciandos que foram tomados como sujeitos da presente pesquisa, indica que, mesmo tendo participado da etapa de formação em argumentação, esta 
não foi suficiente para conferir-lhes grande desenvoltura na busca do objetivo proposto para as regências: propiciar aos estudantes da Educação Básica oportunidades para argumentar na sala de aula.

- os licenciandos enfrentaram dificuldades no que diz respeito ao planejamento e implementação das atividades argumentativas, tais como a postura passiva dos alunos na Educação Básica, acostumados com aulas no formato tradicional, e o tempo usualmente maior requerido para a realização das referidas atividades.

- as estratégias engendradas por parte dos licenciandos, AL e $\mathrm{AE}$, trazem em seu bojo características que as colocam como passíveis de promoção da argumentação, seja porque estimulam a análise e elaboração de hipóteses, seja porque viabilizam relatos, discussões e ponderações, inerentes à atividade científica, sobre a resolução de um determinado problema.

- quanto às ações pró-argumentação, apesar da aplicação de duas diferentes estratégias de ensino, as ações levadas a cabo com maior recorrência pelos licenciandos guardaram semelhanças entre si. Destacaram-se aquelas alinhadas com o contexto de sala de aula tradicionalmente conhecido dos mesmos, por exemplo, a de fornecer evidências aos alunos (4b), muito próxima do discurso de IRF. ${ }^{19}$ Dessa forma, as ações pró-argumentação mais complexas e que requeriam dos licenciandos maior envolvimento e desenvoltura foram realizadas em quantidade pouco significativa.

As conclusões mencionadas permitem que sejam apontadas as seguintes implicações do trabalho:

- é necessário que os cursos de formação de professores desenvolvam ações que se iniciem com o oferecimento de subsídios teóricos sobre a argumentação aos licenciandos e perdurem a partir da retomada dos assuntos tratados e por meio da reflexão sobre a prática pedagógica.

- diante dos obstáculos enfrentados pelos licenciandos no desenvolvimento da prática argumentativa fica patente a necessidade de discussões voltadas para maneiras de superação desses empecilhos nos cursos de formação.

- é preciso promover na formação inicial de professores discussões sobre demais elementos que envolvem a prática argumentativa, como pontos de conflito cognitivo, abordagem de temas do cotidiano e o domínio do alunado sobre os conteúdos científicos que baseiam os assuntos em estudo.

- é desejável que diferentes estratégias promissoras na promoção da argumentação sejam abordadas em cursos de formação, como por exemplo, casos investigativos ${ }^{34}$ e aprendizagem cooperativa no formato jigsaw. ${ }^{35}$ Cabe, no entanto, ponderar as dificuldade dos licenciandos na promoção da argumentação, mesmo a partir do uso da $\mathrm{AL}$ e da $\mathrm{AE}$, que lhes são familiares, sugerindo que se tivessem partido de estratégias não tão usuais, as dificuldades poderiam ser maiores ainda, o que implica em considerar tal aspecto nos cursos de formação.

- $\quad$ o fato da maioria das ações pró-argumentação identificadas ser de tipos que mais se alinham com o contexto tradicional de sala de aula aponta um grande desafio a ser vencido nos cursos de formação, que é preparar os licenciandos para uso de tais ações, porém de natureza mais arrojada. Nesse contexto, a simulação de regências e posterior discussão e reflexão sobre elas, de forma colaborativa com os colegas e com o professor formador, na intenção de avaliar as ações pró-argumentação realizadas e propor alternativas para sua ampliação são promissoras. Ou seja, existe a necessidade de explicitamente indicar para os licenciandos tipos de ações pró-argumentação passíveis de colocação em ação durante as regências e discutir o grau de dificuldade embutido em cada uma delas, bem como meios de superação.
- infelizmente, no que tange ao próprio oferecimento de formação em argumentação para o ensino em ciências, em nosso país são poucos os recursos disponíveis para elaboração de iniciativas dessa natureza, diferentemente do que se observa no âmbito internacional, em que o suporte para a organização de atividades está presente desde a década passada. A título de exemplo, citamos o documento intitulado Resources for introducing argumentation and the use of evidence in science classrooms,${ }^{36}$ produzido pelo grupo RODA (Reasoning, Discourse, Argumentation), vinculado à Universidade de Santiago de Compostela, Espanha. Nessa perspectiva, a produção no Brasil de textos com viés similar viria a preencher uma importante lacuna.

Por fim, acreditamos que a pesquisa aqui reportada, embora realizada com número restrito de sujeitos, traz elementos que poderão contribuir na formação inicial de professores de química para a prática argumentativa.

\section{REFERÊNCIAS}

1. Platin, C.; Tecné, Episteme y Didaxis: TED 2014, 36, 95.

2. Chiaro, S.; Leitão, S.; Psicologia: Reflexão e Crítica 2005, 18, 350.

3. Walker, J. P.; Sampson, V.; Journal of Research in Science Teaching 2013, 50, 56 .

4. Ibraim, S. S.; Justi, R.; Ciência \& Educação 2017, 23, 995.

5. Lourenço, A. B.; Ferreira, J. Q.; Queiroz, S. L.; Quim. Nova 2016, 39, 513.

6. Leite, B. S.; Quim. Nova 2019, 42, 702.

7. Gonçalves, F. P.; Marques, C. A.; Quim. Nova 2011, 34, 899.

8. Lourenço, A. B.; Queiroz, S. L.; Weinberger, A.; Proceedings of the $3^{\text {rd }}$ International Baltic Symposium on Science and Technology Education (BalticSTE2019), Siauliai, Lituânia, 2019.

9. Barro, M. R.; Baffa, A.; Queiroz, S. L.; Quim. Nova Esc. 2014, $36,4$.

10. Oliveira, A. S.; Soares, M. H. F. B.; Quim. Nova Esc. 2005, 21, 18.

11. Suart, R. C.; Marcondes, M. E. R.; Lamas, M. F. P.; Quim. Nova Esc. 2010, 32, 200.

12. Bardin, L.; Análise de Conteúdo; Edições 70: Lisboa, 2006.

13. Simon, S.; Erduran, S.; Osborne, J.; International Journal of Science Education 2006, 28, 235.

14. Biscoli, I. A.; Dissertação de Mestrado, Universidade Federal de Santa Catarina, Brasil, 2005.

15. Soares, M. H. F. B.; Tese de Doutorado, Universidade Federal de São Carlos, Brasil, 2004.

16. Fujii, R. S.; Revista Contexto \& Educação 2011, 26, 102.

17. Zanon, D. A. V.; Guerreiro, M. A. S.; Oliveira, R. C.; Ciências \& Cognição 2008, 13, 72 .

18. Migdalek, M. J.; Rosemberg, C. R.; Santibáñez Yáñez, C.; Íkala, Revista de Lenguaje y Cultura 2014, 19, 251.

19. Amaral, E. M. R.; Scott, P. H.; Mortimer, E. F.; Resumos do IV Encontro Nacional de Pesquisa em Educação em Ciências, Belo Horizonte, Brasil, 2003.

20. Ferreira, L. H.; Hartwig, D. R.; Oliveira, R. C.; Quim. Nova Esc. 2010, 32,101 .

21. Cruz, A. A. C.; Ribeiro, V. G. P.; Longhinotti, E.; Mazzetto, S. E.; Quim. Nova Esc. 2016, 38, 167.

22. Zômpero, A. F.; Laburú, C. E.; Revista Ensaio 2011, 13, 67.

23. Araújo, M. S. T.; Abib, M. L V. S.; Rev. Bras. Ensino Fis. 2003, 25, 176.

24. Souza, R. F.; Tese de Doutorado, Universidade de São Paulo, Brasil, 2018.

25. Souza. F. L.; Akahoshi, L. H.; Marcondes, M. E. R.; Carmo, M. P.; Atividades experimentais investigativas no ensino de química, Centro Paula Souza - Setec/MEC: São Paulo, 2013.

26. https://cdcc.usp.br/experimentoteca, acessada em julho 2020. 
27. Colombo Jr., P. D.; Lourenço, A. B.; Sasseron, L. H.; Carvalho, A. M. P.; Investigações em Ensino de Ciências 2012, 17, 489.

28. Toulmin, S.; Os usos do argumento; Guarany, R., trad.; Martins Fontes: São Paulo, 2001

29. Capecchi, M. C. V. M.; Carvalho, A. M. P.; Investigações em Ensino de Ciências 2000, 5, 171.

30. Oliveira, G. A.; Silva, F. C.; Quim. Nova Esc. 2017, 39, 162.

31. National Research Council; $A$ framework for $K-12$ science education: Practices, crosscutting concepts, and core ideas. National Academies Press: Washington, DC, 2012.

32. http://basenacionalcomum.mec.gov.br, acessada em julho 2020.
33. Chen, Y.; Mineweaser, L.; Accetta, D.; Noonan, D.; J. Coll. Sci. Teach. 2018, 47,22

34. Passos, K.; Campo, L. F.; Daniel, D. P.; Lima, F. S. C.; Passos, C. G.; Quim. Nova 2018, 41, 1209.

35. Silva, G. B.; Teodoro, D. L.; Queiroz, S. L.; Investigações em Ensino de Ciências 2019, 24, 1.

36. Aleixandre, M. P. J.; Otero, J. R. G.; Santamaría, F. E.; Mauriz, B. P.; Resources of introducing argumentation and the use of evidence in science classrooms. University of Santiago de Compostela: Santiago de Compostela, 2009. 